\title{
Gravity structure of Akan composite caldera, eastern Hokkaido, Japan: Application of lake water corrections
}

\author{
Takeshi Hasegawa ${ }^{1}$, Akihiko Yamamoto ${ }^{2}$, Hiroyuki Kamiyama $^{3}$, and Mitsuhiro Nakagawa ${ }^{1}$ \\ ${ }^{1}$ Department of Natural History Sciences, Graduate School of Science, Hokkaido University, Sapporo, Japan \\ ${ }^{2}$ Department of Earth Sciences, Graduate School of Science and Engineering, Ehime University, Matsuyama, Japan \\ ${ }^{3}$ Institute of Seismology and Volcanology, Graduate School of Science, Hokkaido University, Sapporo, Japan
}

(Received October 1, 2008; Revised January 6, 2009; Accepted January 9, 2009; Online published August 31, 2009)

\begin{abstract}
Akan volcano, eastern Hokkaido, Japan, is characterized by a rectangular-shaped caldera (Akan caldera: 24 km by $13 \mathrm{~km}$ ) with a complex history of caldera-forming eruptions during the Quaternary. A new Bouguer anomaly map of the caldera is presented on the basis of a gravity survey around Akan volcano. As part of and in addition to this survey, we applied gravimetry over the frozen caldera lake including lake water corrections. The Bouguer map shows the distribution of at least three sub-circular minima indicative of multiple depressions inside the caldera. Lake water corrections, performed by a numerical integration method using rectangular prisms, sharpen edges of the sub-circular minima. This gravity feature is consistent with geological investigations suggesting that caldera-forming eruptions of Akan volcano occurred from at least three different sources. It is concluded that Akan caldera can be described as a composite caldera with three major depressed segments.

Key words: Gravity anomaly, Akan volcano, composite caldera, lake water correction.
\end{abstract}

\section{Introduction}

Gravity studies have widely been used to constrain subsurface structures and formation processes of caldera volcanoes (e.g., Yokoyama and Ohkawa, 1986; Froger et al., 1998; Gudmundsson and Högnadóttir, 2007). These studies demonstrate that calderas formed by explosive eruptions are generally marked by gravity lows that are interpreted as a lack of mass due to depression structures inside the caldera. In terms of gravity anomalies, however, most of these studies ignored the effect of caldera-filling lake water. Because terrain corrections are commonly computed by using digital elevation models (DEM), which lack water depth information of lakes, the Bouguer correction consists of the replacement of the lake water with rock material. These calculations lead to an overcompensation of the Bouguer anomaly, which depends on the size and depth of the caldera-filling lakes. Although several studies concern water effects caused by relatively large-sized caldera lakes (e.g., Davy and Caldwell, 1998), they do not show the calculating procedures in detail. Some studies also simplify the procedures by replacing lake geometry as an inverted flat-bottomed cone (e.g., Fournier et al., 2004). In the case of relatively small-sized lakes water effects have been ignored because it is likely that the correction may not change the overall trend of gravity structure. However, in order to discuss smaller-scale complex structure and related formation processes of a caldera volcano, accurate and detailed gravity maps are needed.

Akan volcano, located in eastern Hokkaido, Japan

Copyright (c) The Society of Geomagnetism and Earth, Planetary and Space Sciences (SGEPSS); The Seismological Society of Japan; The Volcanological Society of Japan; The Geodetic Society of Japan; The Japanese Society for Planetary Sciences; TERRAPUB.
(Fig. 1), has a rectangular-shaped caldera (Akan caldera: $24 \mathrm{~km}$ by $13 \mathrm{~km}$ ) with a complex, long eruptive history of caldera-forming eruptions (Hasegawa and Nakagawa, 2007). Relatively small-sized caldera lakes (e.g., Lakes Akan, Panke-toh and Onne-toh: a dozen $\mathrm{km}^{2}$ in area) are present at the basin. Although the gravity investigation by Ohkawa and Yokoyama (1979) showed that Akan caldera is characterized by an oval-shaped gravity low, fine-scaled features remain unclear due to the lack of lake water corrections and poor spatial distribution of the gravity stations. In order to reveal the fine gravity structure and formation mechanism of the characteristic rectangular caldera, we performed additional gravity surveys (including those on the frozen lake) and quantitative lake water corrections. In this paper, we present a new gravity map of Akan volcano showing that the caldera is composed of at least three distinct depression segments. In addition, we discuss the significance of lake water corrections of caldera lakes.

\section{Geological Background}

Akan volcano is situated at the southern end of AkanShiretoko volcanic chain, eastern Hokkaido, Japan (Fig. 1). It consists of a caldera (Akan caldera) and four post-caldera volcanoes. Somma lavas with K-Ar ages of 3.9-2.8 Ma (NEDO, 1992; Goto et al., 2000) constitute the rim of Akan caldera, and these presumably represent pre-caldera stratovolcanoes. The basement of Akan volcano consists of Cretaceous-Tertiary sedimentary and volcanic rocks, part of which is characteristically exposed at the center of the caldera basin. Measured densities of the basement rocks were reported as $2.27 \times 10^{3} \sim 2.60 \times 10^{3} \mathrm{~kg} \mathrm{~m}^{-3}$ (NEDO, 1992).

The construction of Akan volcano was initiated by build- 


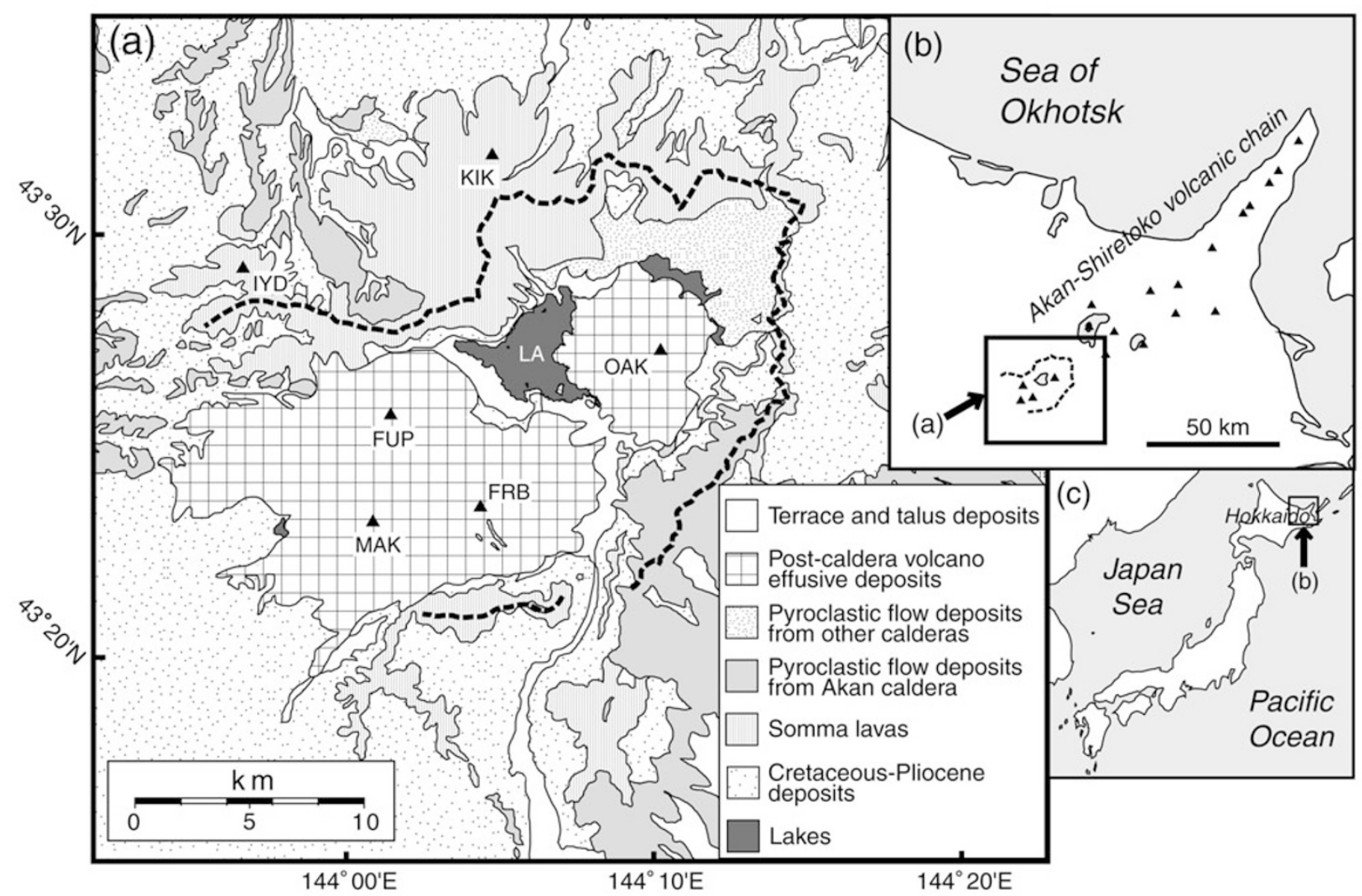

Fig. 1. (a) Simplified geological map of Akan volcano based on Hasegawa et al. (2006), and maps of (b) eastern Hokkaido and (c) Japanese Islands. Closed triangles and dashed lines in (a) represent major summits and topographic rim of Akan caldera, respectively. Triangles in (b) indicate major Quaternary volcanoes. Note that Cretaceous-Pliocene rocks are exposed at the basin of the Akan caldera. Abbreviations; OAK: Mt. O-Akan-dake, MAK: Mt. Me-Akan-dake, FUP: Mt. Fuppushi-dake, FRB: Mt. Furebetsu-dake, KIK: Mt. Kikin-dake, IYD: Mt. Iyudaninupuri-yama, LA: Lake Akan.

ing of the pre-caldera volcanoes, followed by large-scale caldera-forming activities. The caldera-forming activities continued for more than 1 million years (ca. 1.4-0.2 Ma: Hasegawa and Nakagawa, 2007), producing a large volume of pyroclastic flow and fall deposits (Akan pyroclastic deposits) that are widely distributed around the caldera. These pyroclastic deposits are divided into 40 eruptive units, each separated by significant time intervals that are often marked by paleosols (Hasegawa and Nakagawa, 2007). Total eruptive volume of the pyroclastic deposits is estimated to be more than $150 \mathrm{~km}^{3}$ DRE (Hasegawa et al., 2006). Postcaldera volcanoes were generated successively after the latest caldera-forming activity. Volcanic materials discharged from these post-caldera volcanoes widely filled the caldera basin, and then resulted in formation of several dammed lakes. Lake Akan, the largest of these caldera-filling lakes, has an area of $13 \mathrm{~km}^{2}$ and maximum depth of approximately $50 \mathrm{~m}$.

\section{Methods}

\subsection{Gravity survey}

We obtained 15 gravity data on the frozen lake surface and 184 data on land using the Scintrex gravimeters (S227 and S315) with a precision of $\pm 0.05 \mathrm{mGal}$ (reproducibility error). Elevations were determined using differential GPS positioning, spot heights and contours on 1/25,000 topographic maps published by Geographical Survey Institute of Japan. This amounts to 509 gravity data points including published data of Geological Survey of Japan (GSJ) (2000, 2004) and unpublished data of Hokkaido University. The data were reduced for free-air and Bouguer corrections as well as for terrain effects imposing a density of $2.4 \times$ $10^{3} \mathrm{~kg} \mathrm{~m}^{-3}$, which is the median value of actual densities of basement rocks of Akan volcano (NEDO, 1992). Terrain corrections are based on the method of Yamamoto (2002).

\subsection{Lake water correction}

Since the water of the lake is regarded as rock, conventional terrain corrections using DEM without water-depth data (TCWD) are always over- or under-estimated. This excess (insufficient) correction should be canceled by subtracting (adding) the amount of mass difference between water and rock integrated over the whole lake area. This can be achieved by (1) modeling lake water mass by a stack of right rectangular prisms with appropriate grid spacing, and by (2) numerically integrating their gravitational effects. When the grid spacing of this mass prism model is small enough, the error by this approximation on numerical integration may be negligible. To realize this idea, we first digitized bathymetric isopleths of Lake Akan from the $1 / 10,000$-scaled paper-media bathymetric map of the lake. The isopleths were then subject to a $20 \mathrm{~m}$ spacing grid using the 'surface' command of the GMT software (Wessel and Smith, 1995) resulting in a digital bathymetry model of Lake Akan. We computed the gravitational attraction 

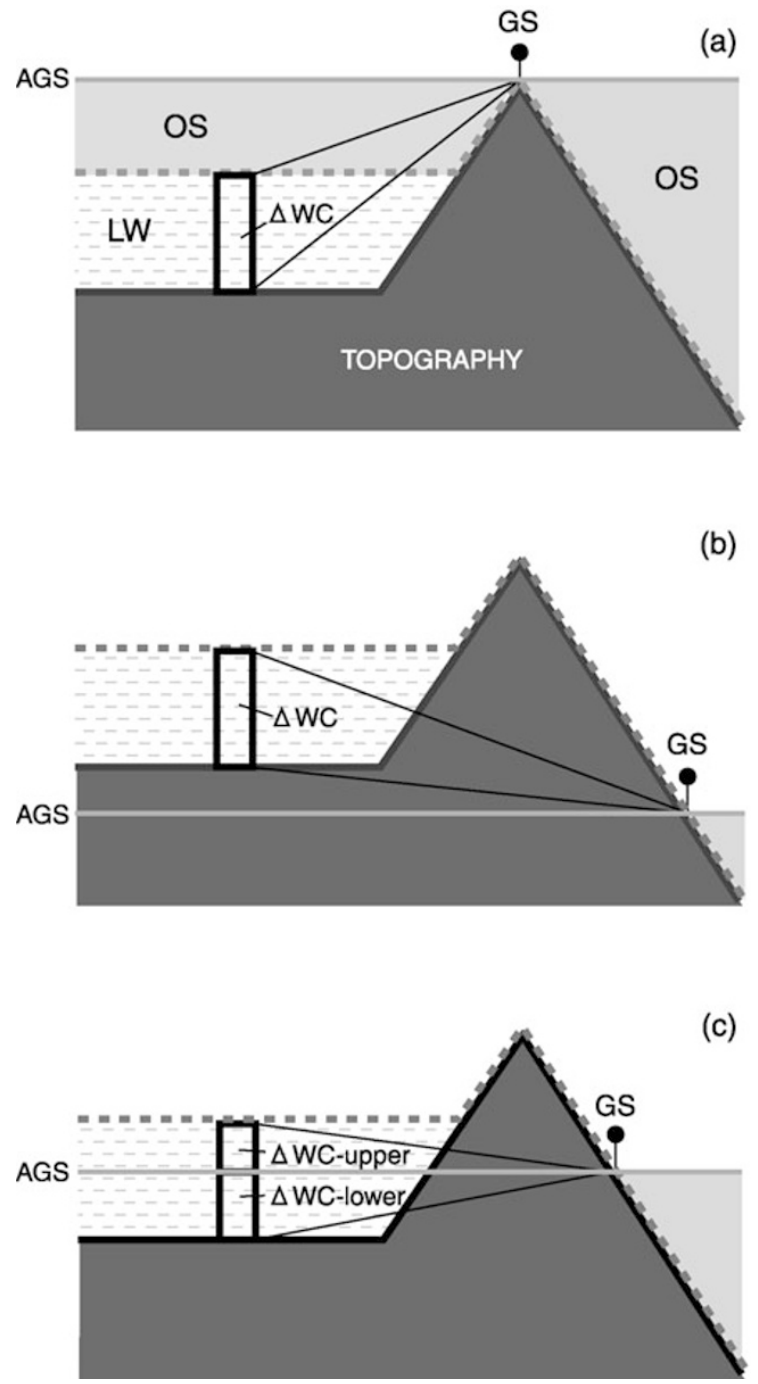

Fig. 2. Schematic illustration of the geometry of lake water corrections The situations that need to be considered are those in which the altitude of gravity stations (AGS: light-gray solid horizontal lines) is (a) higher than that of lake surface, (b) lower than that of lake bottom, and (c) ranging from that of lake bottom to the surface. Topography and lake water (LW) are shown by dark shaded and crossbars-filled patterns, respectively. GS: gravity station, OS: open space (light shade patterns), $\triangle \mathrm{WC}$ : vertical column of lake water having the density difference of $1.4 \times 10^{3}\left(=2.4 \times 10^{3}-1.0 \times 10^{3}\right) \mathrm{kg} \mathrm{m}^{-3}$. Conventional terrain corrections are performed along the boundary between OS and LW/rocks (topography) bounded by solid dotted lines because DEM includes no water-depth information. The effects of LW are calculated by numerical integrals over vertical columns $(\Delta W C)$ of lake water $(\mathrm{LW})$, so that $\mathrm{LW}$ recovers over (or under) -corrected component of conventional terrain correction.

caused by one vertical prism at each gravity station on the basis of the 'TC50' program of Yamamoto (2002). The sum of the contributions from each rectangular prism produces total lake water corrections in a single gravity station. Thus we can carry out the calculation of gravitational effects of whole lake water $\left(1.0 \times 10^{3} \mathrm{~kg} \mathrm{~m}^{-3}\right.$ in density $)$ of Lake Akan by numerical integration in all gravity stations. In practice, we considered the following three cases depending on the elevation difference between the gravity stations and the lake surface: (a) altitude of a gravity station (AGS) is higher than that of the lake surface, (b) AGS is lower than that of the lake bottom, and (c) AGS is ranging from that of the lake bottom to its surface. Figure 2 shows a schematic illustration of the three different cases. Gravity correction idea is simple and as follows: Bouguer slab between sea level and station model is made with terrain correction at first, and Bouguer slab is removed with Bouguer correction later. Although the effects of open space (OS) should be terrain correction, lake water (LW) is not corrected with the conventional DEMs because no water-depth information is included in Japanese DEMs of topography. Therefore, the terrain correction values of LW in case (a) (mass deficit) and (b) (mass surplus) are positive and negative, respectively. These over- and under-subtracted contributions should be recovered for TCWD as the lake water correction. This can be evaluated as a sum of the effect of rectangular prisms $(\triangle \mathrm{WC})$ whose density is given by 1.4 $\times 10^{3} \mathrm{~kg} \mathrm{~m}^{-3}\left(=2.4 \times 10^{3}-1.0 \times 10^{3} \mathrm{~kg} \mathrm{~m}^{-3}\right)$. In the case (c), both the cases (a) and (b) should be considered at the same time. This is because $\triangle \mathrm{WC}$ exists below and above AGS (Fig. 2(c)); it consists of positive and negative parts. In this case, $\triangle \mathrm{WC}$-lower (below AGS) and $\triangle \mathrm{WC}$ upper (above AGS) should be added to and subtracted from TCWD respectively.

\section{Results}

Figure 3(a) shows the contour map of estimated lake water corrections around Lake Akan. In this map, there is no area of negative values of lake effect (case (b) in Fig. 2). The pattern of equi-contour lines on the lake is very much similar to that of bathymetric map of the lake (Fig. 3(b)). The correction values are almost same, or a little small, as the lake depth multiplied with $1.4(2.4-1.0)$ by 0.04192 $(2 \pi \mathrm{G})$. The lake water effects gradually increase as water depth increases, and reach the largest value (about 2 miligals) at the eastern region of the lake, where water depth also reaches the maximum value (approximately $50 \mathrm{~m}$ ). Outside the lake, the effects are mostly less than $0.1 \mathrm{mGal}$ (The minimum effect value in studied area is about $1.0 \times$ $\left.10^{-4} \mu \mathrm{Gals}\right)$. We also estimated lake correction by using $10 \mathrm{~m}$ grid spacing model of the lake, in order to assess the sensitivity for the grid resolution. There is no significant change of the contour map from that of $20 \mathrm{~m}$ grid model (maximum difference value at the same point is about 1.0 $\times 10^{-1} \mu$ Gals).

Figures 4(a) and (b) show a comparison of Bouguer anomaly maps around Lake Akan before and after the lake corrections, respectively. In both maps, two centers of low gravity are recognized at the south of Lake Akan. The lake water corrections remarkably changed the contour pattern of the region between the two lows; a high gravity ridge between the two sub-circular minima was emphasized, and separation of the two minima became more apparent. Distribution of the gravity ridge separating the two minima is in accordance with surrounding geology; basement rocks narrowly exposed along the gravity ridge (Figs. 1 and 4).

Figure 4(c) is a new Bouguer anomaly map of Akan volcano with lake water corrections. There exist the areas of negative values of lake effect (case (b) in Fig. 2) in this map. General features of the maps are summarized as follows: (1) Akan caldera is characterized by a gravitational low that takes its minimum value (about $60 \mathrm{mGal}$ ) in the 

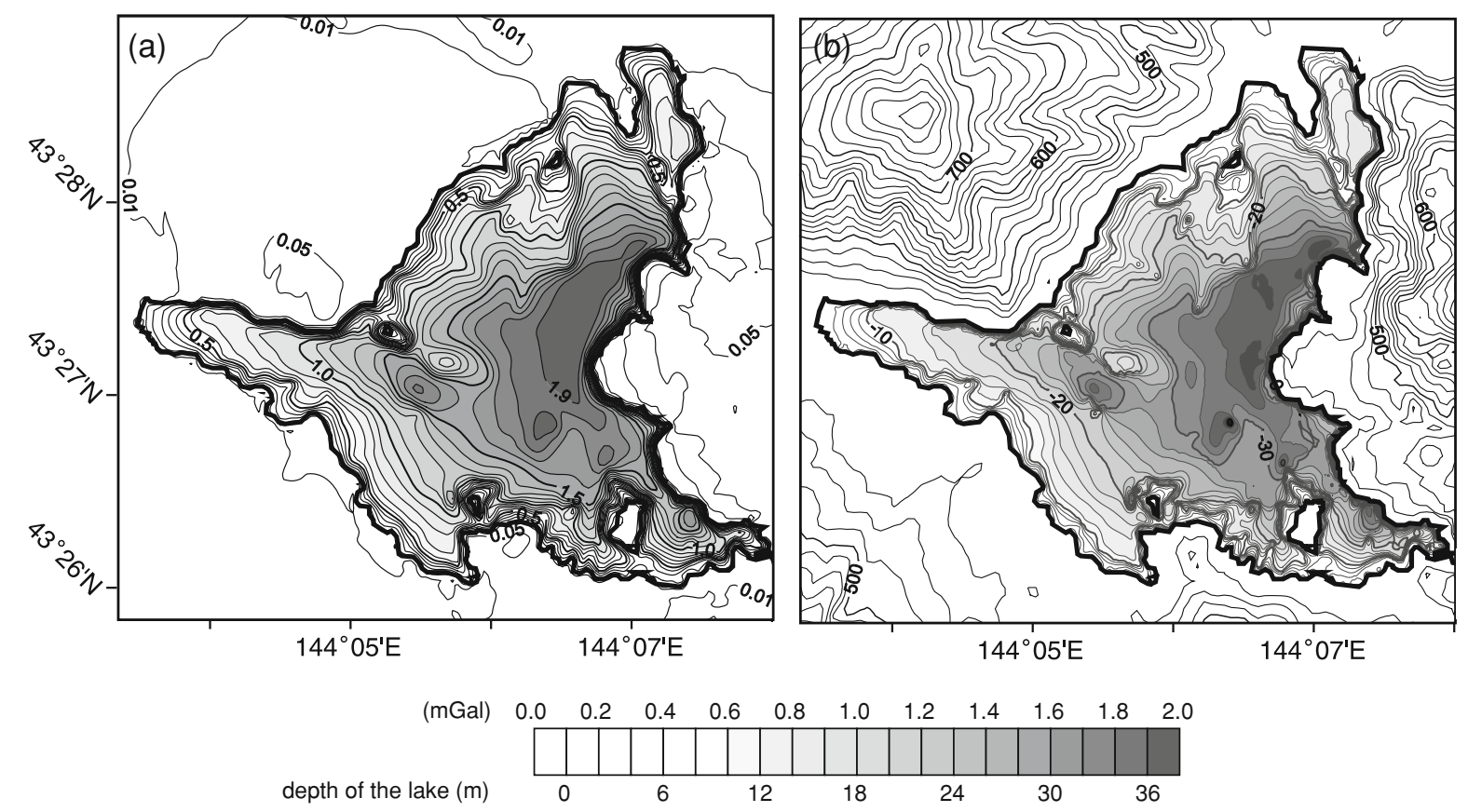

Fig. 3. Contour map showing the effect of lake water correction (a) and topographic map (b) around Lake Akan. Heavy black lines indicate coasts of Lake Akan and four islands (= $420 \mathrm{~m}$ above sea level). The contour interval inside the lake of (a) is $0.1 \mathrm{mGal}$. The reduction density is $2.4 \times$ $10^{3} \mathrm{~kg} \mathrm{~m}^{-3}$. Topographic contours inside and outside the lake of (b) are expressed as bathymetry and above sea level, respectively. The contour intervals of the former and the latter are $2 \mathrm{~m}$ and $20 \mathrm{~m}$, respectively.

center of the caldera; (2) This value gradually increases towards topographic caldera rim and reaches its maximum around the rim; (3) The gravitational low region inside the caldera is composed of at least three sub-circular closed minima. The geometry of this minima is several kilometers long trending in a ENE-WSW direction. These features are also apparent when reduction densities of $2.2 \times 10^{3}$ and $2.67 \times 10^{3} \mathrm{~kg} \mathrm{~m}^{-3}$ are used (The maximum difference of Bouguer anomaly value at the same points when changing the reduction densities $2.2 \sim 2.4 \times 10^{3} \mathrm{~kg} \mathrm{~m}^{-3}$ and $2.4 \sim$ $2.67 \times 10^{3} \mathrm{~kg} \mathrm{~m}^{-3}$ is about $\left.10 \mathrm{mGal}\right)$.

\section{Discussion}

Gravity lows associated with silicic calderas are generally attributed to the caldera infilling within depressed structures by pyroclastic rocks (e.g., Yokoyama, 1963; Rymer and Brown, 1986). The new Bouguer anomaly map of Akan volcano shows that the caldera is characterized by three closed gravitational lows. This suggests that there are three distinct major depressions filled by pyroclastic rocks inside the caldera. A geological study of Akan pyroclastic deposits (Hasegawa and Nakagawa, 2007) suggests that Akan caldera might be a composite one because of the rectangular shape and its long, complex eruptive history. Hasegawa et al. (2006) also inferred that Akan pyroclastic deposits were derived from at least three different vent areas, on the basis of the method of component analysis of lithic fragments used by Suzuki-Kamata et al. (1993) and Cole et al. (1998). These suggestions of geological studies are well consistent with the result of our gravitational investigation.

Although basement rocks are generally not exposed at the bottom of low gravity anomaly type calderas, there exist Tertiary basement rocks at the center of the basin of Akan caldera. Distribution of the basement rock corresponds to the region of a gravitational ridge between two eastern subcircular closed minima (Figs. 1 and 4), suggesting that the ridge of high gravity may be caused by a remnant mass of the denser basement rock. This basement rock can be interpreted as part of a buried caldera rim bounding the distinct caldera depressions.

On the basis of these gravity data combined with previous geological studies, it is concluded that Akan caldera is a composite caldera, whose rectangular shape reflects a distribution of spatially distinct, and relatively small calderas, trending east-west. Composite calderas evidenced by geological and geophysical studies, especially by gravimetric study, were already reported in Japan (e.g. Aso caldera: Komazawa, 1995). Another instance of a composite one is reported in Taupo volcano located on Taupo Volcanic Zone, North Island, New Zealand (e.g., Wilson, 1993; Cole et al., 1998; Davy and Caldwell, 1998).

Recently, Lipman (2000) and Cole et al. (2005) emphasized that many calderas are geometrically complex, containing elements of more than a single structural type and formation processes envisaged by the classical piston and funnel models proposed after Williams and McBirney (1979) and Lipman (1997). Furthermore, multiple magma bodies rather than a single large one are increasingly recognized as an important element that leads to composite structures with complex geometries (e.g., Reubi and Nicholls, 2005; Smith et al., 2005). The case of Akan caldera is one of the good examples supporting the recently-emphasized complex system of caldera formation.

Using our method of lake water corrections, distinct depressed structure was confirmed as a result of canceling a gravitational low (Figs. 4(b) and 4(c)), although this kind 


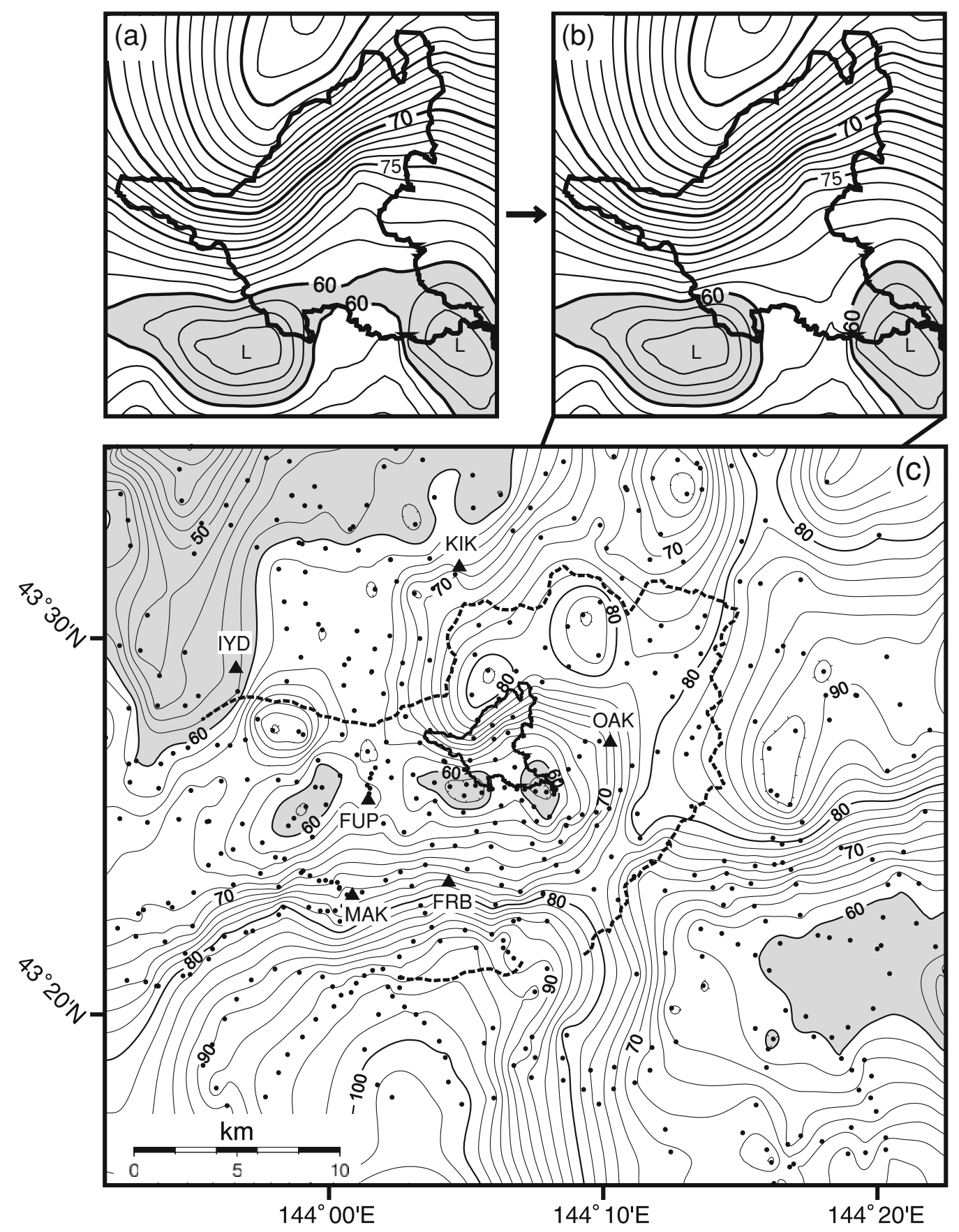

Fig. 4. Bouguer anomaly maps of Akan volcano: close views around Lake Akan (a) before and (b) after the lake water corrections, with contour intervals of $1 \mathrm{mGal}$, and (c) an overview after the lake water correction, with contour intervals of 2 mGal. Reduction density is $2.4 \times 10^{3} \mathrm{~kg} \mathrm{~m}^{-3}$. Solid lines indicate the coasts of Lake Akan. Hachured areas show a Bouguer gravity anomaly less than 60 mGal. Dots and triangles in (c) indicate gravity stations and major summits, respectively. See the caption of Fig. 1 for the abbreviations.

of correction generally tend to obscure a structure of low gravity anomaly type calderas. Since the maximum lake water effects are estimated to be $2 \mathrm{mGal}$ even on a relatively small-sized Lake Akan (Fig. 3), greater changes of gravity features can be expected in case of relatively largesized lakes. Caldera lake water is an obstacle for making gravity maps in terms of difficulty of measuring gravity on the lake surface and complicated procedure of water correction. However, high-resolution gravity investigation including quantitative lake corrections is necessary, even for a small-sized lake, to determine exact gravity features of calderas, whose internal structures and formation processes might not be simple but complex.

Acknowledgments. We thank J. R. Brown of the Department of Geophysics, Stanford University for reading our manuscript. Thanks are also due to the editor of EPS A. Takada, and to N. Fournier and anonymous reviewer for constructive comments. This study was supported by the Fukada Grant-in-Aid from Fukada Geological Institute.

\section{References}

Cole, J. W., S. J. A. Brown, R. M. Burt, S. W. Beresford, and C. J. N. Wilson, Lithic types in ignimbrites as a guide to the evolution of a caldera complex, Taupo volcanic centre, New Zealand, J. Volcanol. 
Geotherm. Res., 80, 217-237, 1998.

Cole, J. W., D. M. Milner, and K. D. Spinks, calderas and caldera structure: a review, J. Volcanol. Geotherm. Res., 69, 1-26, 2005.

Davy, B. W. and T. G. Caldwell, Gravity, magnetic and seismic surveys of the caldera complex, Lake Taupo, North Island, New Zealand, $J$. Volcanol. Geotherm. Res., 81, 69-89, 1998.

Fournier, N., H. Rymer, G. Williams-Jones, and J. Brenes, Highresolution gravity survey: investigation of subsurface structures at Poás volcando, Costa Rica, Geophys. Res. Lett., 31, L15602, doi:10. 1029/2004GL020563, 2004.

Froger, J.-L., J.-F. Lénat, J. Chorowicz, J.-L. Le Pennec, J.-L. Bourdier, O. Köse, O. Zimitoglu, N. M. Gündogdu, and A. Gourgaud, Hidden calderas evidenced by multisource geophysical data; example of Cappadocian Calderas, Central Anatolia, J. Volcanol. Geotherm. Res., 185, 99-128, 1998.

Goto, Y., A. Funayama, N. Gouchi, and T. Itaya, K-Ar ages of the AkanShiretoko volcanic chain lying oblique to the Kurile trench: Implications for the tectonic control of volcanism, Island Arc, 9, 204-218, 2000.

GSJ (Geological Survey of Japan), Gravity CD-ROM of Japan (CD-ROM), Digital Geoscience Map Series P-2, Geol. Surv. Jpn., Tsukuba, Ibaraki., 2000.

GSJ (Geological Survey of Japan), Gravity CD-ROM of Japan (ver. 2) (CD-ROM), Digital Geoscience Map Series P-2, Geol. Surv. Jpn., Tsukuba, Ibaraki, 2004.

Gudmundsson, M. T. and Th. Högnadóttir, Volcanic systems and calderas in the Vatnajökull region, central Iceland: Constraints on crustal structure from gravity data, J. Geodyn., 43, 153-169, 2007.

Hasegawa, T. and M. Nakagawa, Stratigraphy of Early to Middle Pleistocene pyroclastic deposits around Akan caldera, eastern Hokkaido, Japan, J. Geol. Soc. Jpn., 113, 53-72, 2007 (in Japanese with English abstract).

Hasegawa, T., E. Ishii, and M. Nakagawa, Evolution of Akan Caldera, East Hokkaido, indicated by analysis of lithic fragments in pumice fall deposits, The Earth (Chikyu) Monthly, 28, 283-289, 2006 (in Japanese).

Komazawa, M., Gravimetric analysis of Aso Volcano and its interpretation, J. Geod. Soc. Jpn., 41, 17-45, 1995.

Lipman, P. W., Subsidence of ash-flow calderas: relation to. caldera size and chamber geometry, Bull. Volcanol., 59, 198-218, 1997.

Lipman, P. W., Calderas, in Encyclopedia of Volcanoes, edited by H. Sigurdsson et al., 643-662, Academic Press, San Diego, 2000.

NEDO (New Energy and Industrial Technology Development Organiza- tion), Akan area, Report of Geothermal development promotion survey, 26, 1133 pp., New Energy and Indus. Technol. Dev. Org., Kawasaki, Kanagawa, 1992 (in Japanese).

Ohkawa, S. and I. Yokoyama, Subsurface structure of Akan caldera based on gravity anomalies, Geophys. Bull. Hokkaido Univ., 38, 17-29, 1979 (in Japanese with English Abstract).

Reubi, O. and I. A. Nicholls, Structure and dynamics of a silicic magmatic system associated with caldera-forming eruptions at Batur Volcanic Field, Bali, Indonesia, J. Petrol., 46, 1367-1391, 2005.

Rymer, H. and G. C. Brown, Gravity fields and the interpretation of volcanic structures: geological discrimination and temporal evolution, $J$. Volcanol. Geotherm. Res., 27, 229-254, 1986.

Smith, V. C., P. Shane, and I. A. Nairn, Trends in rhyolite geochemistry, mineralogy and magma storage during the last $50 \mathrm{kyr}$ at Okataina and Taupo volcanic center, Taupo Volcanic Zone, New Zealand, J. Volcanol. Geotherm. Res., 148, 372-406, 2005.

Suzuki-Kamata, K., H. Kamata, and C. R. Bacon, Evolution of the calderaforming eruption at Crater Lake, Oregon, indicated by component analysis of lithic fragments, J. Geophys. Res., 98(B8), 14059-14074, 1993.

Wessel, P. and W. H. F. Smith, New version of the generic mapping tools released, EOS Trans. AGU, 76, 329, Suppl., Aug. 15, 1995.

Williams, H. and A. R. McBirney, Calderas and cauldrons, in Volcanology, 207-238, Freeman, Cooper and Co., San Francisco, 1979.

Wilson, C. J. N., Stratigraphy, chronology, styles and dynamics of late Quaternary eruptions from Taupo volcano, New Zealand, Phil. Trans. R. Soc. London, A343, 205-306, 1993.

Yamamoto, A., Spherical terrain corrections for gravity anomaly using a digital elevation model gridded with nodes at every $50 \mathrm{~m}, J$. Fac. Sci. Hokkaido Univ., 11, 845-880, http://eprints.lib.hokudai.ac.jp/ dspace/bitstream/2115/8866/1/11\%286\%29_p845-880.pdf, 2002.

Yokoyama, I., Volcanic calderas and Meteorite craters with the special relation to their gravity anomalies, J. Fac. Sci. Hokkaido Univ., 2, $37-$ 47, 1963.

Yokoyama, I. and S. Ohkawa, The subsurface structure of the Aira Caldera and its vicinity in southern Kyushu, Japan, J. Volcanol. Geotherm. Res., 30, 253-282, 1986.

T. Hasegawa (e-mail: hasegawatakeshi@mail.sci.hokudai.ac.jp), A. Yamamoto, H. Kamiyama, and M. Nakagawa 